\title{
REFERENTIAL COMMUNICATION ABILITIES IN CHILDREN WITH 22Q11.2 DELETION SYNDROME
}

Ellen Van Den Heuvel ${ }^{1}$, Christina Reuterskiöld ${ }^{2}$, Cynthia Solot $^{3}$, Eric Manders ${ }^{1}$, Ann Swillen ${ }^{4,5}$ and Inge Zink ${ }^{1,6}$

Corresponding and first author:

Ellen Van Den Heuvel

E-mail: ellen.vandenheuvel@med.kuleuven.be

${ }^{1}$ KU Leuven, Faculty of Medicine

Department of Neurosciences, Research Group Experimental Oto-Rhino-Laryngology (ExpORL)

Herestraat 49 box 721, B-3000 Leuven, Belgium $+3216379140$

${ }^{2}$ New York University

Department of Communicative Sciences and Disorders

665 Broadway 924, New York, NY 10012, USA

${ }^{3}$ The Children's Hospital of Philadelphia

Center for Childhood Communication

5th Floor Buerger Building

3500 Civic Center Boulevard, Philadelphia, PA 19104, USA

${ }^{4}$ KU Leuven, Faculty of Medicine

Department of Human Genetics

Herestraat 49, box 602, B-3000 Leuven, Belgium

${ }^{5}$ University Hospital Leuven, Campus Gasthuisberg

Center for Human Genetics

Herestraat 49, B-3000 Leuven, Belgium

${ }^{6}$ University Hospital Leuven, Campus Sint-Rafaël

Department of Oto-Rhino-Laryngology, Head \& Neck Surgery, MUCLA

Herestraat 49, B-3000 Leuven, Belgium 


\section{Abstract}

Purpose This study describes the performance on a perspective- and role-taking task in 27 children, ages 6-13, with 22q11.2 deletion syndrome (22q11.2DS). A cross-cultural design comparing Dutch- and English-speaking children with 22q11.2DS explored the possibility of cultural differences.

Method Chronologically age-matched and younger typically developing (TD) children matched for receptive vocabulary served as control groups to identify challenges in referential communication.

Result The utterances of children with 22q11.2DS were characterised as short and simple in lexical and grammatical terms. However, from a language use perspective, their utterances were verbose, ambiguous and irrelevant given the pictured scenes. They tended to elaborate on visual details and conveyed off-topic, extraneous information when participating in a barrier-game procedure. Both types of aberrant utterances forced a listener to consistently infer the intended message. Moreover, children with 22q11.2DS demonstrated difficulty selecting correct speech acts in accordance with contextual cues during a role-taking task.

Conclusion Both English- and Dutch-speaking children with 22q11.2DS showed impoverished information transfer and an increased number of elaborations, suggesting a cross-cultural syndrome-specific feature.

Keywords: referential communication, 22q11.2 deletion syndrome, cross-cultural 


\section{INTRODUCTION}

Using language effectively for social and functional purposes entails identifying what to say in a given situation (Bishop \& Adams, 1991; Nilsen, Mangal, \& MacDonald, 2012). Referential communication (RC) involves the ability to convey essential information taking into account the listener's perspective and is closely connected to the development of Theory of Mind (Abbeduto, Short-Meyerson, Benson, \& Dolish, 2004; de Villiers, 2007; Miller, 2006; Resches \& Perez Pereira, 2007). Perspective-taking refers to the ability to discover 'common ground' or shared information. Speakers must select unambiguous words to prevent miscomprehension, which leads to communicative breakdowns (Clark \& Wilkes-Gibbs, 1986; Clark, 1996). Referential communication also requires a speaker to consider the perspective of others in order to appropriately select and express speech acts (e.g. statement, question, command) according to contextual cues (i.e. role-taking). Both perspective-taking and roletaking abilities advance remarkably during the school-age childhood years (6 to 9 years old) and are essential for accurate judgment of the listeners' informational demands (e.g. Clark \& Svaib, 1997; Lloyd, Camaioni, \& Ercolani, 1995; Lloyd, Mann, \& Peers, 1998).

Since RC relies on both linguistic and socio-cognitive abilities, children with intellectual disability (ID) have an increased risk for challenges in this domain. Limitations in perspective- and role-taking abilities have a direct impact on daily communication and may lead to social-emotional issues when a child cannot express his intended feelings or thoughts (Hatton, 1998; Rondal, 2001). Research regarding RC and speech act expression in heterogeneous groups of children with ID has indicated a delayed rather than a deviant pattern compared to typically developing children (Abbeduto \& Hesketh, 1997; Abbeduto \& ShortMeyerson, 1997). However, in particular groups of children with genetic disorders, more significant impairments have been demonstrated. In children with fragile X, Down syndrome and Williams syndrome several behaviours have been found to cause miscomprehension. 
These include limitations in synchronising descriptions of events to the informational needs of the listener, difficulties structuring descriptions or providing an increased amount of irrelevant statements (Abbeduto et al., 2006; Asada, Tomiwa, Okada, \& Itakura, 2010; Skwerer, Ammerman, \& Tager-Flusberg, 2013).

Until now, perspective-taking and role-taking abilities have not been explored in children with 22q11.2 deletion syndrome (22q11.2DS). This syndrome, sometimes referred to as velocardiofacial syndrome or DiGeorge syndrome, is the most common microdeletion syndrome with an incidence of 1:2000 to 1:4000 live births (Botto et al., 2003; McDonaldMcGinn \& Sullivan, 2011). Intellectual disability occurs in $50 \%$ of individuals diagnosed with the syndrome (Swillen et al., 1997). Children with 22q11.2DS are also characterised by a broad spectrum of medical, physical, behavioural and cognitive challenges and strengths (e.g. Shprintzen et al., 1978; Swillen, Vogels, Devriendt, \& Fryns, 2000; Vogels \& Fryns, 2002; Woodin et al., 2001). Speech and language impairments are frequently reported in this group (Antshel, Marrinan, Kates, Fremont, \& Shprintzen, 2009; Glaser et al., 2002; Solot et al., 2000, 2001).

Generally, children with 22q11.2DS demonstrate late onset of language. Glaser et al. (2002), compared school-aged children and adolescents with 22q11.2DS to IQ-matched children with developmental delay (DD). In the 22q11.2DS group the receptive language skills were found to be weaker than expressive language skills, while the opposite was observed in the DD group. Other authors however did not find evidence for a considerable discrepancy between receptive and expressive language in school-aged children (Gerdes et al., 1999; Moss et al., 1999; Solot et al., 2001). Wide within-group variability in language abilities, changing language profiles over time and continued challenges in some linguistic areas in this population may impact several academic skills (e.g. reading comprehension, [mathematical] problem-solving). Socio-communicative problems were indicated by means of parent 
questionnaires (Angkustsiri et al., 2014; Antshel et al., 2007; Van Den Heuvel, Manders, Swillen, \& Zink, in press). Parents of children with 22q11.2DS are often concerned about the child's (1) inability to use contextual information to understand, organise and express language, (2) inappropriate information transfer including vague word choice and irrelevant elaborations during conversations, and (3) problems with understanding implicit meaning of words (Van Den Heuvel et al., in press).

Research based on direct assessment of socio-communicative or pragmatic language skills in children with 22q11.2DS is limited. Persson et al. (2006) investigated the retelling ability of 19 school-aged children with 22q11.2DS by means of the Bus Story Test (Renfrew, 1997). Reduced number of core information elements, short sentence length and limited use of subordinate clauses were indicated as pivotal narrative challenges. A negative correlation between chronological age (CA) and information scores suggested that older children had more difficulties providing essential event-content of a story. This finding implied that scores of children with 22q11.2DS insufficiently increased leading to a larger discrepancy compared to age-appropriated norms. Failure to concisely convey and organise information may be related to limitations in referential communication skills (Cummings, 2009).

In the present study, we hypothesise that children with 22q11.2DS have delayed or deviant perspective-taking and role-taking abilities. Since pragmatic language skills are likely to be influenced by cultural norms, individuals from different cultures might communicate according to their own interactive norms resulting in socio-cultural pragmatic variation (Norbury \& Sparks, 2012; O'Keeffe, Clancy, \& Adolphs, 2011). Therefore, in the present study, data from Dutch-speaking children living in Belgium or the Netherlands and data from English-speaking children living in the USA were collected and compared. Rather limited, yet not negligible, differences between Northern American and Western European culture are assumed. Social communication is highly influenced by any cultural variation. We aimed to 
explore similarities and (subtle) differences in referential communication skills in children with 22q11.2DS across two different cultures when controlling for assessment procedures and interlocutor. Considering the four maxims of conversation (Grice, 1975), this study analyses the quantity, quality, manner and relevance of information transfer. The overall goal is to gain information about how children with 22q11.2DS select and transmit relevant information in semi-structured tasks. To this end, we address the following questions:

1) While analysing the quantity, quality, manner and relevance of information transfer during perspective-taking and role-taking tasks, is there a difference in the performance of Dutchspeaking and English-speaking children with 22q11.2DS?

2) Do children with 22q11.2DS perform differently compared to TD peers and younger TD children matched for receptive vocabulary?

3) Are perspective-taking and role-taking abilities interrelated and related to age, expressive or receptive language competence in this population?

\section{MeTHOD}

\section{Participants}

Twenty-seven children with 22q11.2DS ( $M_{\mathrm{age}}=9 \mathrm{y} 10 \mathrm{~m}, S D=2 \mathrm{y} 3 \mathrm{~m}$, range: $\left.6 \mathrm{y} 0 \mathrm{~m}-13 \mathrm{y} 09 \mathrm{~m}\right)$, confirmed by means of fluorescence in situ hybridization (FISH) or micro-array (arrayCGH), participated in this study. Dutch-speaking children with 22q11.2DS ( $n=18)$ were recruited through the Centre for Human Genetics, UZ Leuven, Belgium. English-speaking children with 22q11.2DS $(n=9)$ were recruited through the $22 \mathrm{q}$ and You Centre of The Children's Hospital of Philadelphia, Philadelphia, Pennsylvania, USA. Parental consent was obtained for all participants. The study was approved by the institutional review boards of both hospitals, the Catholic University of Leuven as well as by New York University. 
A first study group included 9 English- and 9 Dutch-speaking children, pairwise matched on chronological age (+/- 6 months) and on the standard score (SS) of the Peabody Picture Vocabulary Test-III (+/- $0.5 S D$, maximum of 8 SS difference). The educational level of the mother, was determined by a questionnaire completed by the parents asking for the highest level of education. The International Standard Classification of Education (ISCED) of UNESCO (OECD, 1999) was used to classify the educational level on a six point scale. Educational level was categorised as: low (primary education or lower grades of secondary school), middle (secondary/high school diploma) or high educational level (college or university diploma obtained). Educational level and gender were balanced across groups in order to minimise the possible effect on language results (Eriksson et al., 2012; Letts, Edwards, Sinka, Schaefer, \& Gibbons, 2013). Items of the Dutch CELF-4 (Kort, Compaan, Schittekatte, \& Dekker, 2010) or Dutch CELF Preschool-2 (de Jong, 2012) were matched to items of the English CELF-4 screener (Semel, Wiig, \& Secord, 2004) to establish a comparable Expressive Language Screening Composite Score (ELSCS). The ELSCS was converted into a percentage and used as an estimate for expressive language abilities (see supplementary material for details). No differences for chronological age (CA), PPVT standard scores and ELSCS across groups were demonstrated. One Dutch-speaking child (pair 2) had a confirmed ASD diagnosis. In both the English-speaking and Dutch-speaking group four children (44.44\%) had an ADHD diagnosis. The full-scale IQ (FSIQ) range of Englishspeaking children was 61 to $89(M=73.86, S D=8.57)$ and 51 to $78(M=69.22, S D=8.09)$ for Dutch-speaking children. Group characteristics are summarised in Table I.

\section{**INSERT TABLE I **}

A second study group included 18 Dutch-speaking children with 22q11.2DS, who were compared to 36 typically developing Dutch-speaking children (TD). In this 22q11.2DS group four children had a confirmed ASD diagnosis (22.22\%) and seven had a formal ADHD 
diagnosis $(38.89 \%)$. Children with 22q11.2DS were pairwise matched to 18 peers $(\mathrm{CA},+/-6$ months) and to 18 younger TD children for Receptive Vocabulary Age Equivalents (RVAE, +/- 3 months) measured by means of the PPVT-III-NL (Schlichting, 2005). Receptive vocabulary was chosen since pragmatic language competence, especially inferencing abilities, have been proven to be associated with receptive language skills (Adams, Clarke, \& Haynes, 2009; Perkins, 2007). Gender and educational level of the mother were individually matched across groups. All TD children were selected from mainstream preschools and primary schools. Exclusion criteria were defined as presence of (1) any speech, language or learning difficulty, (2) neonatal abnormalities or neuro-developmental disorders, and (3) hearing or sensory-motor problems (bilateral hearing thresholds $>40 \mathrm{~dB}$ HL). Information regarding these criteria was collected by means of a parental questionnaire and educational reports.

Participants' characteristics are provided in Table II.

**INSERT TABLE II**

Velopharyngeal impairment (VPI) is a common feature of children with 22q11.2DS (GoldingKushner, 1985; Rommel et al., 1999; Solot et al., 2001) and may affect speech intelligibility. Intelligibility is an important component of effective communication. All children with 22q11.2DS $(n=27)$ were rated for intelligibility by perceptual evaluation and/or nasometry ratings. Intelligibility was rated on a three point scale: within normal limits, mild to moderate, and severely unintelligible. In eight children (29.63\%) speech intelligibility was found to be within normal limits. In twelve children (44.44\%) intelligibility was mildly to moderately impaired, and in seven children (25.93\%) intelligibility was severely impaired.

\section{Measures and procedures}

Dutch-speaking children were assessed at school or at home. English-speaking children were assessed at The Children's Hospital of Philadelphia. Both tasks were individually administered by the first author in a quiet room, a proficient Dutch-English bilingual speaker. 


\section{Perspective-taking task}

\section{Instrument}

An effective unambiguous information transfer allows a listener to easily receive, decode and understand the intended meaning (Leinonen \& Letts, 1997). This competence was evaluated by means of the Dutch adaptation of the of the Action Picture Test (APT, Renfrew, 1997) as described in the Renfrew Language Scales Dutch Adaptation (RTNA, Jansonius et al., 2014). This standardised assessment presents a barrier-game procedure to evaluate how children convey information about ten coloured pictures, depicting daily situations. The examiner closed her eyes and asked the child to pick a (trial) card. During the trial phase, the examiner explained she could not see what was in the picture. Two trial items demonstrated the purpose of the task and the child was encouraged to refer to characters and actions and to use specific words. After receiving feedback on the trial items, children were required to convey information about 10 pictured scenes. The child picked a card and the examiner asked "What is happening?". The child was instructed to signal the examiner when he/she transferred his/her intended message by saying “That's it!” ('Dat is het!')” or “Ready!” ('Klaar!').

\section{Analysis}

Performance was analysed in two ways:

(1) Quality and quantity of information transfer: This was evaluated using the 'Information Transfer Score' (ITS). A maximum score of 100 was possible following adequate transfer of information about 10 pictured scenes. Individual item scores differed according to the complexity of the pictured situation. Core elements (specific words) were awarded 2 points, less specific words were scored 1 point and vague or incorrect words were not counted. The number of utterances used to transfer the intended message was counted as well. According to Bishop \& Adams (1991), children with pragmatic impairments might (1) use too few 
utterances resulting in incomplete information transfer or (2) transfer too much information or excessively elaborate upon the topic confusing the listener. Mean length of utterance (MLU) and mean length of five longest utterances (ML5LU) were used as a parameter for productivity. MLU and ML5LU were counted in full words and compound nouns were counted as one word. Perseverations (i.e. repetition of the same information) were excluded for analysis.

(2) Manner and relevance of information transfer: This was captured by coding all utterances according to five categories. Operational definitions and criteria to classify responses are summarised in Table III.

**INSERT TABLE III**

\section{Role-taking task}

\section{Instrument}

Eight items from the 'Communicative Role-Taking' (CRT) task of the Dialect Sensitive Language Test (DSLT, Seymour, Roeper, \& de Villiers, 2000), a pilot version of the Diagnostic Evaluation of Language Variation (DELV-NR, Seymour, Roeper, \& de Villiers, 2005), were used in this study. The CRT subtest measures the child's ability to take the communicative role of a speaking character. In addition, the child has to be sensitive to contextual cues and prompts provided by the examiner to convey an adequate message (de Villiers, 2004). For every item a sequence of two events was shown (Figure 1). First, the examiner pointed to one picture and prompted the child to focus on the event ("Look at what's happening there"). Next, a second picture showed the character from the first picture saying something to a new character. Then, the child was asked what the speaking character would tell, ask or say to the other person. The examiner emphasised the type of 
communicative utterance needed in the prompt (e.g. What is the girl telling her mother?). The items used in the present study asked the child to express two statements, two questions and four commands.

** INSERT FIGURE 1**

Analysis

No comprehensive quantitative or qualitative response analysis is provided in the DELV manual. Therefore, four response categories were defined (see Table IV). A maximum score of 16 was established to indicate optimal role-taking ability. Proportions of type of answers reflected manner and relevance of information transfer.

** INSERT TABLE IV**

\section{Reliability}

Language samples of both perspective-taking and role-taking tasks of all English-Dutch 22q11.2DS pairs ( $n=18,28 \%$ of total sample) were video recorded, transcribed and evaluated by two coders and scores were compared. Inter-rater reliability was assessed using a two-way mixed, absolute-agreement model (Hallgren, 2012). Intraclass correlation values (ICC, see supplementary material for details) indicated a high degree of similarity (ICC values range: $.83-.98)$. According to the guidelines of Cicchetti (1994), values $>.75$ are considered to represent excellent agreement. Therefore, consistency in coding and clarity of the coding categories of the Action Picture Test and Communicative Role-Taking was demonstrated.

\section{Data analysis}

In both studies several variables violated the assumption of normality (Shapiro-Wilk Test < $.05)$ or homogeneity of variance (Levene's test $<.05$ ). Since transformation of raw data containing numerous zero values could not correct skewness and due to small sample sizes, 
non-parametric tests were preferred for all analyses. To account for the dependent nature of data (i.e. individually matched pairs), data were analysed by Wilcoxon Signed Rank Tests. False Discovery Rate control (FDR, Benjamini \& Hochberg, 1995) was used to overcome Type-I errors in multiple comparisons. Effect sizes were calculated by the formula $r=z / \sqrt{ } \mathrm{n}$ (Field, 2013). Spearman correlations $\left(r_{\mathrm{S}}\right)$ were used to clarify the relationships between chronological age (CA), Receptive Vocabulary Age Equivalents (RVAE), educational level and Expressive Language Screening Composite Scores (ELSCS). Cohen's guidelines (Cohen, 1988) were used to evaluate the strength of the relationship. Coefficients above .40 (i.e. moderate to strong association) are reported. Bruining et al. (2010) demonstrated that ASD combined with a specific genotype is found to be different from ASD without a clear underlying genetic cause. Consequently, the children with 22q11.2DS + ASD were not excluded for analysis.

\section{RESULT}

\section{Perspective-taking and role-taking in 22q11.2DS: cross-cultural findings}

\section{Quality and quantity of information transfer}

No significant differences in information transfer scores (ITS) were found $(T=17.00, p=$ .514). The median ITS of the APT in the English-speaking 22q11.2DS group was 79.00, with an interquartile range $(I Q R)$ of $64.00-81.50$, and overall range of 22.00-87.00. A similar median score of 79.00 was found in the Dutch-speaking 22q11.2DS group but different IQR (70.50-83.50) and range of scores (59.00-87.00) were indicated.

In general, English-speaking and Dutch-speaking children with 22q11.2DS used about 24 utterances to describe the 10 pictured scenes. Great individual differences were observed in both groups with a range from 19 to 42 utterances. No differences were demonstrated between groups for mean length of utterance (MLU, $T=36.00, p=.110$ ) and mean length of utterances of five longest utterances (ML5LU, $T=29.00, p=.123$ ). Group median for MLU 
was $6.58(I Q R=5.86-7.32$, range $=3.13-9.96)$ and 10.50 words for ML5LU $(I Q R=8.95-$ 12.05, range $=4.40-18.20)$. The median Communicative Role-Taking $(\mathrm{CRT})$ total score for the English speaking 22q11.2DS group was $11.00(I Q R=8.50-12.50$, range: $0.00-13.00)$ and $13.00(I Q R=7.50-14.00$, range $=6.00-16.00)$ for Dutch-speaking children with 22q11.2DS . No significant difference was demonstrated (CRT total score, $T=10.00, p=.497$ ).

Manner and relevance of information transfer

The Action Picture Test type of utterance categorisation revealed that in both groups about half of all utterances were complete sentences and referred to core information elements (Tunits). About one third or more of the utterances was considered to be a logical elaboration and one quarter or less was found to be off-topic (Figure 2). The Dutch-speaking 22q11.2DS group produced more T-units compared to the English-speaking 22q11.2DS group. These differences were not found to be significantly different. However, English-speaking children with 22q11.2DS made significantly more associative elaborations than Dutch-speaking children with 22q11.2DS $(T=45.00, p=.008, r=-.63,95 \%$ CI $[-.84,-.23])$.

\section{**INSERT FIGURE 2**}

Analysis of the types of Communicative Role-Taking answers demonstrated no significant differences. Generally, children with 22q11.2DS produced 53\% correct answers (A answers), $15 \%$ vague answers (B1 answers), 12\% answers with inaccurate communicative function (B2 answers), and $15 \%$ off-topic answers (C answers). There was only one child in the Englishspeaking group who did not understand the purpose of the task after multiple repetitions of the instructions and refused participation. This child was also found to have the lowest information transfer score.

\section{Comparison with typically developing children}

Quality and quantity of information transfer 
Children with 22q11.2DS had significantly lower information transfer scores than CA TD controls. No significant difference was found when comparing with RVAE TD controls. Children with 22q11.2DS used significantly more utterances and produced shorter sentences. No differences in communicative role-taking total scores of were indicated (Table V).

**INSERT TABLE $V^{* *}$

\section{Manner and relevance of information transfer}

Several significant differences were found across groups in how information was transferred to the listener. Figure 3 shows differences in distributions of proportions of elaborations across groups.

\section{**INSERT FIGURE 3**}

Descriptive statistics for proportions of T-units and I-units are summarised in Table VI. Children with 22q11.2DS did not exhibit a significantly lower number of correct A answers in the role-taking task. However, they used significantly more inaccurate communicative functions than CA matched TD children. The number of off-topic answers was elevated as well but not found to be significantly higher (Table VI).

**INSERT TABLE VI**

Relationship between perspective-taking, role-taking and age, receptive vocabulary and expressive language across groups

Fewer strong relationships between CA and perspective-taking and role-taking measures were found in the 22q11.2DS group compared to TD children. However, significant strong relationships between receptive vocabulary age equivalents and several measures were demonstrated (Table VII). In the 22q11.2DS group, the number of emotional elaborations in Action Picture Test (APT) was positively correlated with the Communicative Role-Taking (CRT) total score $\left(r_{s}=.51, p=.007\right)$ and the number of correct A answers $\left(r_{s}=.59, p=.001\right)$. A higher number of illogical elaborations in the APT task was correlated with a lower CRT 
total score $\left(r_{s}=-.64, p<.001\right)$ and a lower number of correct answers $\left(r_{s}=-.61, p=.001\right)$. In TD children a higher amount of APT T-units was related to a decreased level of visual $\left(r_{s}=-\right.$ $.57, p<.001)$ and associative elaborations $\left(r_{s}=-.59, p<.001\right)$. This negative association was not found in children with 22q11.2DS.

**INSERT TABLE VII**

\section{DISCUSSION}

Performance of children with 22q11.2DS on the perspective-taking task was significantly poorer compared to TD peers. Children with 22q11.2DS transferred less essential information and used shorter, less grammatically complex sentences. This finding corroborates the results of Persson et al. (2006), reporting on lexically and grammatically impoverished narratives. However, a significantly higher number of utterances was demonstrated. Children with 22q11.2DS seldom used cohesive devices, which resulted in a chain of unconnected utterances. Compared to both chronological age (CA) and younger Receptive Vocabulary Age Equivalent (RVAE) matched TD children, children with 22q11.2 DS produced less complete sentences containing core message components (T-units). Compared to younger RVAE matched controls, they added significantly more information regarding visual details. Frequent use of irrelevant elaborations made the contributions of children with 22q11.2DS ambiguous and confusing.

Role-taking posed fewer challenges. Nonetheless, children with 22q11.2DS performed closer to younger TD when selecting the appropriate speech act given the context. Similar characteristics were noted in English-speaking and Dutch-speaking children with 22q11.2DS. The only significant difference found between the English-speaking and Dutch-speaking group, i.e. a higher number of associative elaborations in English-speaking children, may be due to subtle differences in child rearing and educational approaches. Based on rather anecdotal evidence, we hypothesise that children in the USA were more explicitly told to be 
straightforward and to emphasise implications. Dutch-speaking (Belgian) children are more often implicitly channelled towards the targeted communicative behaviour. Further studies are required to verify this hypothesis. Hence, it is implied that the observed socio-communicative behaviours may be syndrome-specific and are not likely to be explained solely by cultural variation. Several explanations for these challenges can be put forth. First, poor structural language skills and particularly, limitations in language comprehension, may lead to poor referential communication skills. Some authors have reported on syndrome-specific language comprehension problems in primary-school aged children with 22q11.2DS (Glaser et al., 2002; Solot et al., 2001). Additionally, there is evidence that language impaired children with receptive language difficulties as well as children with speech sound disorders with comorbid language impairment exhibit an increased number of irrelevant utterances during narrative tasks (Wagner Reuterskiöld, Sahlén, \& Nettelbladt, 1999; Wellman et al., 2011). Indeed, the correlational data suggest that language proficiency might be a potential factor affecting referential communication abilities in children with 22q11.2DS. While language delays could partially account for the pragmatic differences compared to age peers, they cannot explain the atypical verbosity and differences compared to younger RVAE matched controls. The data corroborate with the pattern of difficulties seen in children with pragmatic language impairments, which do not all show structural language deficits (Bishop \& Norbury, 2002; Bishop, 2000; Botting \& Conti-Ramsden, 1999). Speech intelligibility did not significantly account for within-group differences observed in children with 22q11.2DS. There was a tendency for children with severely impaired intelligibility to express fewer utterances during the Action Picture Test.

Given the particular error patterns, it seems likely that visual information processing and judgment of communicative relevance in children with 22q11.2DS differs from TD children. Previous studies demonstrated abnormalities in visual scanpath strategies for both socio-facial 
stimuli as well as complex pictures. Children with 22q11.2DS demonstrated shorter fixation time, leading to inaccurate information processing (Campbell et al., 2010; Glaser et al., 2010; McCabe, Rich, Loughland, Schall, \& Campbell, 2011). This may explain the focus on visual details and the increased amount of illogical utterances triggered by deficient visual interpretation. Additionally, the relationship between emotional elaborations and Communicative Role-Taking total scores suggests that children with 22q11.2DS who were more sensitive to emotions of characters (i.e. facial scanning) effectively captured the speaker's intended purpose resulting in more correct answers in the role-taking task.

Judging what is appropriate or inappropriate to share, requires insight into the listener's need for information. This might be attributed to a delay in the decline of egocentrism (Epley, Morewedge, \& Keysar, 2004; Karmiloff-Smith, 1979; Keysar, Barr, \& Horton, 1998). When a child is not yet able to take into account the difference between his or her own perspective and the perspective of others, utterances will be less informative to a listener since a child uses his/her own knowledge as the common ground perspective. Additionally, the increased amount of associative and irrelevant elaborations often related to personal experiences are likely to be a reflection of an egocentric perspective.

There are some limitations associated with the present study. The small sample size and the absence of a comparison group matched on non-verbal IQ scores limit the study's contribution to our understanding of the 22q11.2DS population. Further research should incorporate a comparison with children with cognitive impairments in order to control for the effects of non-verbal cognitive skills. Further, some participants in the 22q11.2DS group had comorbid autism spectrum disorders (ASD), which may have impacted performance on the referential communication tasks (Dahlgren \& Dahlgren Sandberg, 2008). Research is needed to identify differences and similarities in socio-communication behaviours between children with 22q11.2DS only and children with a comorbid ASD. An additional limitation is the 
reliance on two short and semi-structured activities in which semantic and pragmatic demands are rather consistent (Reuterskiöld Wagner, Nettelbladt, \& Sahlen, 2001). The tasks may not have been sensitive enough to capture all of the constraints children with 22q11.2DS experience in real-life interactions. Norbury (2014) mentioned that evaluation of sociocommunicative behaviour should include: (1) formal assessments of pragmatic language skills, (2) structured observation of conversation, and (3) parents teacher reports to obtain detailed insight in the everyday communicative challenges of the child. Applying multiple methods and multiple informants is essential to describe the disharmonic sociocommunicative and language profile of children with 22q11.2DS (Wray, Shashi, Schoch, Curtiss \& Hooper, 2013).

Some clinical recommendations can be cautiously drawn from this investigation. Poor management of reference for the listener and poor interpretation of contextual cues are likely to be closely related to the weaker social competence of individuals with 22q11.2DS that has been reported in previous research (e.g. Swillen et al., 1997; Campbell, McCabe, Melville, Strutt, \& Schall, 2015). Underlying social-cognitive deficits are assumed to be a precipitating factor for these limitations and socio-cognitive remediation is suggested for enhancing sociocommunicative skills and overall quality of life (Demily et al., 2015; Swillen \& McDonaldMcGinn, 2015). However, (longitudinal) research is needed to delineate the most effective management for individuals with 22q11.2DS in different stages of life. Efficacy of sociocognitive remediation and its impact on socio-communicative behaviour should be further explored.

\section{CONCLUSION}

This study provides evidence for aberrant utterances in perspective- and role-taking tasks in primary-school age children with 22q11.2DS. These behaviours are likely to make these 
children more vulnerable for socio-communicative breakdowns. The results highlight a particular component of expressive language production that requires individualised language support. The interplay between auditory processing, visual processing and language use should be further explored, and could lead to a better understanding of the complex behavioural phenotype of children with 22q11.2DS.

\section{ACKNOWLEDGEMENT}

The authors want to thank all participating children and families and speech and language pathologists and teachers of several schools who assisted with recruitment. The authors gratefully acknowledge assistance provided by Claudette Bañares, Mary Gochuico, Nore Wijns and Ine Gomand, for analysis of samples for inter-rater reliability. The authors would also like to thank Prof. Dr. Elaine Zackai, Prof. Dr. Donna McDonald-McGinn and Dr. Oksana Jackson, Children's Hospital of Philadelphia, for their assistance with recruitment of English-speaking children.

Declaration of interest: The authors report no conflicts of interest.

This research was funded by a grant awarded by the foundation Marguerite-Marie Delacroix and a KU Leuven Junior Mobility grant. 


\section{REFERENCES}

Abbeduto, L., \& Hesketh, L. J. (1997). Pragmatic development in individuals with mental retardation: Learning to use language in social interactions. Mental Retardation and Developmental Disabilities Research Reviews, 3, 323-333. doi:10.1002/(SICI)10982779(1997)3:4<323::AID-MRDD7>3.0.CO;2-O

Abbeduto, L., Murphy, M. M., Richmond, E. K., Amman, A., Beth, P., Weissman, M. D., et al. (2006). Collaboration in referential communication: Comparison of youth with Down syndrome or Fragile X syndrome. American Journal of Mental Retardation, 111, 170-183. doi:10.1352/0895-8017(2006)111[170:CIRCCO]2.0.CO;2

Abbeduto, L., \& Short-Meyerson, K. (1997). Signaling of noncomprehension by children and adolescents with mental retardation: Effect of problem type and speaker identity. Journal of Speech, Language, and Hearing Research, 40, 20-33. doi:10.1044/jslhr.4001.20

Abbeduto, L., Short-Meyerson, K., Benson, G., \& Dolish, J. (2004). Relationship between theory of mind and language ability in children and adolescents with intellectual disability. Journal of Intellectual Disability Research, 48, 150-159. doi:10.1111/j.1365-2788.2004.00524.x

Adams, C., Clarke, E., \& Haynes, R. (2009). Inference and sentence comprehension in children with specific or pragmatic language impairments. International Journal of Language \& Communication Disorders, 44, 301-318. doi:10.1080/13682820802051788

Angkustsiri, K., Goodlin-Jones, B., Deprey, L., Brahmbhatt, K., Harris, S., \& Simon, T. J. (2014). Social impairments in chromosome 22q11.2 deletion syndrome (22q11.2DS): Autism spectrum disorder or a different endophenotype? Journal of Autism and Developmental Disorders, 44, 739-746. doi:10.1007/s10803-013-1920-х

Antshel, K. M., Aneja, A., Strunge, L., Peebles, J., Fremont, W. P., Stallone, K. et al. (2007). Autistic spectrum disorders in velo-cardio facial syndrome (22q11.2 deletion). Journal of Autism and Developmental Disorders, 37, 1776-1786. doi:10.1007/s10803-0060308-6

Antshel, K. M., Marrinan, E., Kates, W. R., Fremont, W., \& Shprintzen, R. J. (2009). Language and literacy development in individuals with velo-cardio facial syndrome. Topics in Language Disorders, 29, 170-186. doi:10.1097/TLD.0b013e3181a72084 
Asada, K., Tomiwa, K., Okada, M., \& Itakura, S. (2010). Atypical verbal communication pattern according to others' attention in children with Williams syndrome. Research in Developmental Disabilities, 31, 452-457. doi:10.1016/j.ridd.2009.10.010

Benjamini, Y., \& Hochberg, Y. (1995). Controlling the False Discovery Rate: A practical and powerful approach to multiple test. Journal of the Royal Statistical Society, Series B, 57, 289-300. doi:10.2307/2346101

Bishop, D. V. M. (2000). Pragmatic language impairment: A correlate of SLI, a distinct subgroup, or part of the autistic continuum? In L. B. Leonard \& D. V. M. Bishop (Eds.), Speech language impairments in children: Causes, characteristics, intervention and outcome (pp. 99-113). Hove: Psychology Press.

Bishop, D. V. M., \& Adams, C. (1991). What do referential communication tasks measure? A study of children with specific language impairment. Applied Psycholinguistics, 12, 201-215. doi: 10.1017/S0142716400009140

Bishop, D. V. M., \& Norbury, C. F. (2002). Exploring the boundaries of autistic disorder and specific language impairment: same or different? Journal of Child Psychology and Psychiatry, 43, 916-929. doi:10.1111/1469-7610.00114

Botting, N., \& Conti-Ramsden, G. (1999). Pragmatic language impairment without autism: The children in question. Autism, 3, 371-396. doi:10.1177/1362361399003004005

Botto, L. D., May, K., Fernhoff, P. M., Correa, A., Coleman, K., Rasmussen, S. A., et al. (2003). A population-based study of the 22q11.2 deletion: Phenotype, incidence, and contribution to major birth defects in the population. Pediatrics, 112, 101-107. doi:10.1542/peds.112.1.101

Bruining, H., De Sonneville, L., Swaab, H., De Jonge, M., Kas, M., Van Engeland, H., \& Vorstman, J. A. (2010). Dissecting the clinical heterogeneity of autism spectrum disorder through defined genotypes. PLoS ONE, 5, e:10887.

Campbell, L., McCabe, K., Leadbeater, K., Schall, U., Loughland, C., \& Rich, D. (2010). Visual scanning of faces in 22q11.2 deletion syndrome: Attention to the mouth or the eyes? Psychiatry Research, 177, 211-215. doi:10.1016/j.psychres.2009.06.007

Campbell, L. E., McCabe, K. L., Melville, J. L., Strutt, P. A., \& Schall, U. (2015). Social cognition dysfunction in adolescents with 22q11.2 deletion syndrome (velo-cardiofacial syndrome): Relationship with executive functioning and social competence/functioning. Journal of Intellectual Disability Research, 59, 845-859. doi:10.1111/jir.12183 
Cicchetti, D. V. (1994). Guidelines, criteria, and rules of thumb. Psychological Assessment, 4, 284-290. doi:10.1037/1040-3590.6.4.284

Clark, H. H. (1996). Using language. Cambridge: Cambridge University Press.

Clark, H. H., \& Wilkes-Gibbs, D. (1986). Referring as a collaborative process. Cognition, 22, 1-39. doi:10.1016/0010-0277(86)90010-7

Clark, E. V., \& Svaib, T. A. (1997). Speaker perspective and reference in young children. First Language, 17, 57-74. doi:10.1177/014272379701705103

Cohen, J. (1988). Statistical Power Analysis for the Behavioral Sciences, 2nd Edition. Hillsdale: Lawrence Erlbaum.

Cummings, L. (2009). Clinical pragmatics. Cambridge: Cambridge University Press.

Dahlgren, S., \& Dahlgren Sandberg, A. (2008). Referential communication in children with autism spectrum disorder. Autism, 12, 1335-1348. doi:10.1177/1362361308091648

De Jong, J. (2012). Clinical Evaluation of Language Fundamentals Preschool-2-NL. Nederlandstalige Versie. Handleiding. [CELF-P2-NL, Dutch Edition. Manual]. Amsterdam: Pearson.

Demily, C., Rossi, M., Schneider, M., Edery, P., Leleu, A., d'Amato, T., Franck, N., \& Eliez, S. (2015). Neurocognitive and psychiatric management of the 22q11.2 deletion syndrome. Encephale, 41, 266-273. doi: 10.1016/j.encep.2014.10.005

De Villiers, J. (2007). The interface of language and Theory of Mind. Lingua, 117, 18581878. doi: 10.1016/j.lingua.2006.11.006

De Villiers, P. (2004). Assessing pragmatic skills in elicited production. Seminars in Speech and Language, 25, 57-71. doi:10.1055/s-2004-824826

Epley, N., Morewedge, C. K., \& Keysar, B. (2004). Perspective taking in children and adults: Equivalent egocentrism but differential correction. Journal of Experimental Social Psychology, 40, 760-768. doi:10.1016/j.jesp.2004.02.002

Eriksson, M., Marschik, P. B., Tulviste, T., Almgren, M., Pérez Pereira, M., Wehberg, S., et al. (2012). Differences between girls and boys in emerging language skills: Evidence from 10 language communities. British Journal of Developmental Psychology, 30, 326-343. doi:10.1111/j.2044-835X.2011.02042.x

Field, A. (2013). Discovering statistics using IBM SPSS statistics. Los Angeles, CA: SAGE Publications.

Gerdes, M., Solot, C. B., Wang, P. P., La Rossa, D., Randall, P., Goldmutz, E., et al. (1999). Cognitive and behavior profile of preschool children with chromosome 22q11.2 
deletion. American Journal of Medical Genetics, 85, 127-133.

doi:10.1002/(SICI)1096-8628(19990716)85:2<127::AID-AJMG6>3.0.CO;2-F

Glaser, B., Debbané, M., Ottet, M.-C., Vuilleumier, P., Zesiger, P., Antonarakis, S. E., et al. (2010). Eye gaze during face processing in children and adolescents with 22q11.2 deletion syndrome. Journal of the American Academy of Child \& Adolescent Psychiatry, 49, 665-674. doi:10.1016/j.jaac.2010.04.004

Glaser, B., Mumme, D. L., Blasey, C., Morris, M. a., Dahoun, S. P., Antonarakis, S. E., et al. (2002). Language skills in children with velocardiofacial syndrome (deletion 22q11.2). Journal of Pediatrics, 140, 753-758. doi:10.1067/mpd.2002.124774

Golding-Kushner, K. J., Weller, G., \& Shprintzen, R. J. (1985). Velo-cardio-facial syndrome: Language and psychological profiles. Journal of Craniofacial Genetics and Developmental Biology, 5, 259-266.

Grice, H. P. (1975). Logic and conversation. In P. Cole \& J. L. Morgan (Eds.), Syntax and semantics: Volume 3 Speech Acts (pp. 41-58). New York: Academic Press.

Hallgren, K. A. (2012). Computing inter-rater reliability for observational data: An overview and tutorial. Tutorials in Quantitative Methods for Psychology, 8, 23-34.

Hatton, C. (1998). Pragmatic language skills in people with intellectual disabilities: A review. Journal of Intellectual and Developmental Disability, 23, 79-100. doi:10.1080/13668259800033601

Jansonius, K., Ketelaars, M., Borgers, M., Van Den Heuvel, E., Roeyers, H., Manders, E., \& Zink, I. (2014). Renfrew Taalschalen Nederlandse Aanpassing: Handleiding [ Renfrew Language Scales Dutch Adaptation: Manual]. Antwerpen: Garant.

Karmiloff-Smith, A. (1979). A functional approach to child language: a study of determiners and reference. Cambridge: Cambridge University Press.

Keysar, B., Barr, D. J., \& Horton, W. S. (1998). The egocentric basis of language use: Insights from a processing approach. Current Directions in Psychological Science, 7, 46-50.

Kort, W., Compaan, E. L., Schittekatte, M., \& Dekker, P. H. (2010). Clinical Evaluation of Language Fundamentals Nederlandse versie Handleiding [CELF 4, Dutch Edition, Manual]. Amsterdam: Pearson.

Leinonen, E., \& Letts, C. (1997). Referential communication tasks: performance by normal and pragmatically impaired children. European Journal of Disorders of Communication, 32, 53-65. doi:10.1111/j.1460-6984.1997.tb01624.x 
Letts, C., Edwards, S., Sinka, I., Schaefer, B., \& Gibbons, W. (2013). Socio-economic status and language acquisition: Children's performance on the new Reynell Developmental Language Scales. International Journal of Language and Communication Disorders, 48, 131-143. doi:10.1111/1460-6984.12004

Lloyd, P., Camaioni, L., \& Ercolani, P. (1995). Assessing referential communication skills in primary school years: A comparative study. British Journal of Developmental Psychology, 13, 13-29. doi:10.1111/j.2044-835X.1995.tb00661.x

Lloyd, P., Mann, S., \& Peers, I. (1998). The growth of speaker and listener skills from five to eleven years. First Language, 18, 81-103. doi:10.1177/014272379801805203

McCabe, K., Rich, D., Loughland, C. M., Schall, U., \& Campbell, L. E. (2011). Visual scanpath abnormalities in 22q11.2 deletion syndrome: Is this a face specific deficit? Psychiatry Research, 189, 292-298. doi:10.1016/j.psychres.2011.06.012

McDonald-McGinn, D. M., \& Sullivan, K. E. (2011). Chromosome 22q11.2 deletion syndrome (DiGeorge syndrome/velocardiofacial syndrome). Medicine (Baltimore), 90, 1-18. doi:10.1097/MD.0b013e3182060469

Miller, C. A. (2006). Developmental relationships between language and theory of mind. American Journal of Speech-Language Pathology, 15, 142-154. doi:10.1044/10580360(2006/014)

Moss, E. M., Batshaw, M. L., Solot, C. B., Gerdes, M., McDonald-McGinn, D. M., Driscoll, D.A, et al. (1999). Psychoeducational profile of the 22q11.2 microdeletion: A complex pattern. Journal of Pediatrics, 134, 193-198. doi:10.1016/S0022-3476(99)70415-4

Nilsen, E. S., Mangal, L., \& MacDonald, K. (2012). Referential communication in children with ADHD: Challenges in the role of a listener. Journal of Speech, Language, and Hearing Research, 56, 590-603. doi:10.1044/1092-4388(2012/12-0013)

Norbury, C. F. (2014). Practitioner review: Social (pragmatic) communication disorder conceptualization, evidence and clinical implications. Journal of Child Psychology and Psychiatry, 55, 204-216. doi:10.1111/jcpp.12154

Norbury, C., \& Sparks, A. (2012). Difference of disorder? Cultural issues in understanding neurodevelopmental disorders. Developmental Psychology, 49, 45-58. doi:10.1037/a0027446

O'Keeffe, A., Clancy, B., \& Adolphs, S. (2011). Introducing pragmatics in use. London: Routledge. 
OECD. (1999). Classifying Educational Programmes: Manual for ISCED-97 Implementation in OECD Countries. Paris: Organisation for Economic Co-operation and Development.

Perkins, M. (2007). Pragmatic impairment. Cambridge: Cambridge University Press.

Persson, C., Niklasson, L., Oskarsdóttir, S., Johansson, S., Jönsson, R., \& Söderpalm, E. (2006). Language skills in 5-8-year-old children with 22q11 deletion syndrome. International Journal of Language \& Communication Disorders, 41, 313-333. doi:10.1080/13682820500361497

Resches, M., \& Perez Pereira, M. (2007). Referential communication abilities and Theory of Mind development in preschool children. Journal of Child Language, 34, 21-52. doi:10.1017/S0305000906007641

Reuterskiöld Wagner, C., Nettelbladt, U., \& Sahlen, B. (2001). Giving the crucial information: performance on a referential communication task in Swedish children with language impairment. International Journal of Language \& Communication Disorders, 36, 433-445. doi:10.1080/13682820110074980

Rommel, N., Vantrappen, G., Swillen, A., Devriendt, K., Feenstra, L., \& Fryns, J. P. (1999). Retrospective analysis of feeding and speech disorders in 50 patients with velo-cardiofacial syndrome. Genetic Counseling, 10, 71-78.

Rondal, J. A. (2001). Language in mental retardation: Individual and syndromic differences, and neurogenetic variation. Swiss Journal of Psychology, 60, 161-178. doi:10.1024//1421-0185.60.3.161

Schlichting, L. (2005). Peabody Picture Vocabulary Test-III-NL Nederlandse Versie. Handleiding. [Peabody Picture Vocabulary Test Dutch Edition. Manual.]. Amsterdam: Pearson.

Semel, E., Wiig, E. H., \& Secord, W. A. (2004). Clinical Evaluation of Language Fundamentals - Screening Test - Fourth Edition [CELF - 4 Screening]. San Antonio, TX: Pearson.

Seymour, H., Roeper, T., \& de Villiers, J. (2003). Diagnostic Evaluation of Language Variation [Dutch research adaptation by B. Hollebrandse and A. van Hout]. San Antonio, TX: The Psychological Corporation.

Shprintzen, R. J., Goldberg, R. B., Lewin, M. L., Sidoti, E. J., Berkman, M. D., Argamaso, R. V., et al. (1978). A new syndrome involving cleft palate, cardiac anomalies, typical facies, and learning disabilities: Velo-cardio-facial syndrome. Cleft Palate Journal, 15, 56-62. doi:10.1097/00006534-197811000-00083 
Skwerer, D. P., Ammerman, E., \& Tager-Flusberg, H. (2013). Do you have a question for me? How children with Williams syndrome respond to ambiguous referential communication during a joint activity. Journal of Child Language, 40, 266-289. doi:10.1017/S0305000912000360

Solot, C. B., Gerdes, M., Kirschner, R. E., McDonald-McGinn, D. M., Moss, E. M., Woodin, M. F., et al. (2001). Communication issues in 22q11.2 deletion syndrome: Children at risk. Genetics in Medicine, 3, 67-71. doi:10.1097/00125817-200101000-00015

Solot, C. B., Knightly, C., Handler, S. D., McDonald-McGinn, D. M., Moss, E. M., Wang, P., et al. (2000). Communication disorders in the 22q11.2 microdeletion syndrome. Journal of Communication Disorders, 33, 187-204. doi:10.1016/S00219924(00)00018-6

Swillen, A., Devriendt, K., Legius, E., Eyskens, B., Dumoulin, M., Gewillig, M., \& Fryns, J. P. (1997). Intelligence and psychosocial adjustment in velocardiofacial syndrome: Study of 37 children and adolescents with VCFS. Journal of Medical Genetics, 34, 453-458. doi:10.1136/jmg.34.6.453

Swillen, A., \& McDonald-McGinn, D. (2015). Developmental trajectories in 22q11.2 deletion. American Journal of Medical Genetics Part C (Seminars in Medical Genetics) 169C, 172-181. doi:10.1002/ajmg.c.31435

Swillen, A., Vogels, A., Devriendt, K., \& Fryns, J. P. (2000). Chromosome 22q11 deletion syndrome: update and review of the clinical features, cognitive-behavioral spectrum, and psychiatric complications. American Journal of Medical Genetics, 97, 128-135. doi:10.1002/1096-8628(200022)97:2<128::AID-AJMG4>3.0.CO;2-Z

Van Den Heuvel, E., Manders, E., Swillen, A., \& Zink, I. (in press). Parental report on sociocommunicative behaviours in children with 22q11.2 deletion syndrome. Journal of Intellectual and Developmental Disability.

Vogels, A., \& Fryns, J. P. (2002). The velocardiofacial syndrome: A review. Genetic Counseling, 13, 105-113.

Wagner Reuterskiöld, C., Sahlén, B., \& Nettelbladt, U. (1999). What's the story? Narration and comprehension in Swedish preschool children with language impairment. Child Language Teaching and Therapy, 15, 113-137. doi:10.1177/026565909901500202

Wellman, R. L., Lewis, B. A., Freebairn, L. A., Avrich, A. A., Hansen, A. J., \& Stein, C. M. (2011). Narrative ability of children with speech sound disorders and the prediction of later literacy skills. Language, Speech, and Hearing Services in Schools, 42, 561-579. doi:10.1044/0161-1461(2011/10-0038) 
Woodin, M. F., Wang, P. P., Aleman, D., McDonald-McGinn, D. M., Zackai, E. H., \& Moss, E. M. (2001). Neuropsychological profile of children and adolescents with the 22q11.2 microdeletion. Genetics in Medicine, 3, 34-39. doi:10.1097/00125817-20010100000008

Wray, E., Shashi, V., Schoch, K., Curtiss, K., \& Hooper, S. R. (2013). Discrepancies in parent and teacher ratings of social-behavioral functioning of children with chromosome 22q11.2 deletion syndrome: Implications for assessment. American Journal on Intellectual and Developmental Disabilities, 118, 339-352. doi:10.1352/1944-7558118.5.339 
TABLES

Table I. Background characteristics of the matched English-Dutch pairs with 22q11.2DS

\begin{tabular}{|c|c|c|c|c|c|c|c|c|c|c|}
\hline \multicolumn{6}{|c|}{$\begin{array}{l}\text { English speaking 22q11.2DS group } \\
\qquad(n=9,5 q ; 4 \overbrace{}^{\Uparrow})\end{array}$} & \multicolumn{5}{|c|}{$\begin{array}{l}\text { Dutch speaking 22q11.2DS group } \\
\left(n=9,5+; 4{ }^{\Uparrow}\right)\end{array}$} \\
\hline Pairs & Gender & EL & $\mathrm{CA}^{\mathrm{a}}$ & $\begin{array}{l}\text { PPVT } \\
\text { SS }^{b}\end{array}$ & $\begin{array}{c}\% \\
\text { ELSCS }^{\mathrm{c}}\end{array}$ & Gender & EL & $\mathrm{CA}^{\mathrm{a}}$ & $\begin{array}{l}\text { PPVT } \\
\text { SS }^{\mathrm{b}}\end{array}$ & $\begin{array}{c}\% \\
\text { ELSCS }^{c}\end{array}$ \\
\hline Pair 1 & $\mathrm{~F}$ & $\mathrm{M}$ & 6.1 & 85 & 25.00 & $\mathrm{~F}$ & $\mathrm{M}$ & 6.0 & 83 & 41.67 \\
\hline Pair 2 & M & $\mathrm{L}$ & 6.5 & 67 & 75.00 & $\mathrm{M}$ & $\mathrm{L}$ & 6.6 & 67 & 75.00 \\
\hline Pair 3 & $\mathrm{~F}$ & $\mathrm{~L}$ & 7.2 & 75 & 66.67 & $\mathrm{M}$ & $\mathrm{M}$ & 7.7 & 81 & 75.00 \\
\hline Pair 4 & M & $\mathrm{M}$ & 9.1 & 52 & 83.33 & $\mathrm{M}$ & $\mathrm{L}$ & 9.6 & 55 & 83.33 \\
\hline Pair 5 & $\mathrm{~F}$ & $\mathrm{M}$ & 9.7 & 75 & 50.00 & $\mathrm{~F}$ & $\mathrm{H}$ & 9.5 & 72 & 33.33 \\
\hline Pair 6 & $\mathrm{~F}$ & $\mathrm{H}$ & 9.8 & 79 & 25.00 & $\mathrm{~F}$ & $\mathrm{H}$ & 9.2 & 80 & 41.67 \\
\hline Pair 7 & $\mathrm{~F}$ & $\mathrm{M}$ & 11.6 & 69 & 50.00 & $\mathrm{~F}$ & M & 12.1 & 72 & 50.00 \\
\hline Pair 8 & M & $\mathrm{H}$ & 12.0 & 103 & 66.67 & $\mathrm{~F}$ & $\mathrm{~L}$ & 11.6 & 96 & 58.33 \\
\hline Pair 9 & M & $\mathrm{L}$ & 13.2 & 89 & 91.67 & $\mathrm{M}$ & $\mathrm{L}$ & 13.1 & 81 & 83.33 \\
\hline Median & & & 9.7 & 75 & 66.67 & & & 9.5 & 80 & 58.33 \\
\hline
\end{tabular}

Gender $(\mathrm{F}=$ female, $\mathrm{M}=$ male $)$; $\mathrm{EL}=$ education level of mother $(\mathrm{L}=$ low, $\mathrm{M}=$ middle, $\mathrm{H}=$ high $)$; $\mathrm{CA}=$ chronological age (years.months); PPVT SS = Peabody Picture Vocabulary III Standard Score $(X \sim N$ $(100,15)) ; \%$ Expressive Language Screening Composite Score (ELSCS) based on items of CELF-4Screener, CELF-4-NL or CELF Preschool NL.

${ }^{a}$ No significant CA difference across groups $(T=15, p=.372)$.

${ }^{\mathrm{b}}$ No significant PPVT SS difference across groups $(T=21, p=.673)$.

${ }^{\mathrm{c} N o}$ significant ELSCS difference across groups $(T=10, p=.915)$. 
Table II. Participants' characteristics of Dutch-speaking 22q11.2DS group and typically developing (TD) controls

\begin{tabular}{|c|c|c|c|c|c|c|}
\hline & \multicolumn{2}{|c|}{ 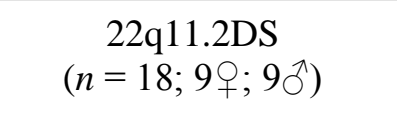 } & \multicolumn{2}{|c|}{  } & \multicolumn{2}{|c|}{$\begin{array}{l}\text { TD RVAE matched } \\
\text { b }\left(n=18 ; 9 \% ; 9{ }^{\Uparrow}\right)\end{array}$} \\
\hline & Median & range & Median & range & Median & range \\
\hline Age (yr.mo) & 9.8 & $6.0-13.7$ & 9.9 & $5.10-13.4$ & 7.2 & $4.7-11.8$ \\
\hline RVAE (yr.mo) & 7.2 & $4.5-11.0$ & $9.7 * *$ & 5.9-12.9 & 7.3 & $4.7-11.0$ \\
\hline$\%$ ELSCS & 62.50 & $33.33-83.33$ & $83.33 * *$ & $58.33-100.00$ & $66.67^{c}$ & $50.00-100.00$ \\
\hline
\end{tabular}

$\mathrm{CA}=$ chronological age; RVAE = Receptive Vocabulary Age Equivalent of PPVT-III-NL

(Schlichting, 2005); ELSCS = Expressive Language Screening Composite Score, based on items of CELF-4-Screener, CELF-4-NL or CELF Preschool NL; yr = years; mo = months.

${ }^{\text {a }}$ Pairwise CA matched, no significant CA difference across groups $(T=41.00, p=.276)$.

${ }^{\mathrm{b}}$ Pairwise RVAE matched, no significant RVAE difference across groups $(T=21.00, p=.852)$.

${ }^{\mathrm{c}}$ No significant difference between RVAE TD group and 22q11.2DS group for \% ELSCS $(T=83.50$, $p=.051)$.** Significant difference between CA TD group and 22q11.2DS group $p<.001$. 
Table III. Definitions and criteria for six types of utterances categories (Action Picture Test)

\begin{tabular}{|c|c|c|c|}
\hline $\begin{array}{l}\text { Response } \\
\text { category }\end{array}$ & Definition & $\begin{array}{l}\text { Additional } \\
\text { criteria }\end{array}$ & $\begin{array}{c}\text { Example } \\
\text { Target utterance Item 1: } \\
\text { A girl is hugging her teddy bear. }\end{array}$ \\
\hline T-unit & $\begin{array}{l}\text { Grammatical phrase } \\
\text { containing core information } \\
\text { (key elements of the target } \\
\text { utterance), subject-verb } \\
\text { agreement is correct. }\end{array}$ & $\begin{array}{l}\text { Morphological } \\
\text { errors against } \\
\text { irregular verb } \\
\text { tenses are } \\
\text { allowed. }\end{array}$ & $\begin{array}{l}\text { The girl is giving the teddy bear a } \\
\text { hug. }\end{array}$ \\
\hline $\begin{array}{l}\text { I-unit } \\
\text { (Information- } \\
\text { Unit) }\end{array}$ & $\begin{array}{l}\text { Ungrammatical phrase (e.g. } \\
\text { verb omission, incorrect } \\
\text { subject-verb agreement) or } \\
\text { fragment referring to core } \\
\text { information. }\end{array}$ & $\begin{array}{l}\text { Verb omission } \\
\text { is allowed. }\end{array}$ & $G i$ \\
\hline $\begin{array}{l}\text { Emotional } \\
\text { elaboration }\end{array}$ & $\begin{array}{l}\text { Utterance referring to an } \\
\text { emotion of a character in } \\
\text { the pictured scene. The } \\
\text { emotion is appropriate } \\
\text { given the pictured context. }\end{array}$ & $\begin{array}{l}\text { Grammatical } \\
\text { or } \\
\text { ungrammatical } \\
\text { utterances } \\
\text { both are } \\
\text { allowed. }\end{array}$ & Maybe she is a bit sad / lonely. \\
\hline $\begin{array}{l}\text { Visual } \\
\text { elaboration }\end{array}$ & $\begin{array}{l}\text { Utterance referring to a } \\
\text { visual detail present in the } \\
\text { picture but not part of the } \\
\text { target sentences (no core } \\
\text { information). The child } \\
\text { focuses on a detail rather } \\
\text { than sharing what is } \\
\text { happening. }\end{array}$ & $\begin{array}{l}\text { Grammatical } \\
\text { or } \\
\text { ungrammatical } \\
\text { utterances } \\
\text { both are } \\
\text { allowed. }\end{array}$ & $\begin{array}{l}\text { She closes her eyes. Her hair is } \\
\text { brown. }\end{array}$ \\
\hline $\begin{array}{l}\text { Associative } \\
\text { elaboration }\end{array}$ & $\begin{array}{l}\text { Utterance referring to (1) a } \\
\text { direct cause or consequence } \\
\text { of the picture or }(2) \\
\text { referring to an event that } \\
\text { logically comes before or } \\
\text { after the pictured event. A } \\
\text { logical cause-effect relation } \\
\text { is expressed. }\end{array}$ & $\begin{array}{l}\text { Grammatical } \\
\text { or } \\
\text { ungrammatical } \\
\text { utterances } \\
\text { both are } \\
\text { allowed. }\end{array}$ & $\begin{array}{l}\text { She sleeps with that bear } \\
\text { sometimes. }\end{array}$ \\
\hline $\begin{array}{l}\text { Illogical } \\
\text { elaboration }\end{array}$ & $\begin{array}{l}\text { Supplemental information } \\
\text { that is (1) not appropriate } \\
\text { taking into account the } \\
\text { information on the picture } \\
\text { (2) not immediately evident } \\
\text { from the picture (not } \\
\text { visible) (3) false / incorrect } \\
\text { information, unclear / } \\
\text { vague / cannot be } \\
\text { understood or paraphrased } \\
\text { by a listener. }\end{array}$ & $\begin{array}{l}\text { Grammatical } \\
\text { or } \\
\text { ungrammatical } \\
\text { utterances } \\
\text { both are } \\
\text { allowed. }\end{array}$ & $\begin{array}{l}\text { She hurt herself so badly that's why } \\
\text { she is crying and her bear too. }\end{array}$ \\
\hline
\end{tabular}


Table IV. Response categories of the Communicative Role-Taking task

\begin{tabular}{llll}
\hline Classification & \multicolumn{1}{c}{ Definition } & Example \\
\hline A answer & $\begin{array}{l}\text { The response is an appropriate } \\
\text { speech act and contains central } \\
\text { features of the pictured event. }\end{array}$ & "I received a letter from the man". & 2 \\
& $\begin{array}{l}\text { The utterance is a correct speech } \\
\text { act, but there is/are central } \\
\text { B1 answer }\end{array}$ & "Here! For you!". \\
& $\begin{array}{l}\text { uses less specific words } \\
\text { resulting in a less informative } \\
\text { message. }\end{array}$ & 1 \\
& $\begin{array}{l}\text { The utterance is related to the } \\
\text { pictured scene, but no proper } \\
\text { communicative function is used. }\end{array}$ & "Who sent you a letter?" \\
B2 answer & $\begin{array}{l}\text { Irrelevant, vague or incomplete } \\
\text { answer. }\end{array}$ & "I'm going to dance now " \\
C answer & &
\end{tabular}


Table V. Descriptive statistics of quality and quantity measures in Action Picture Test (APT) and Communicative Role-Taking (CRT) task across groups

\begin{tabular}{|c|c|c|c|c|c|c|c|c|c|}
\hline \multirow[b]{2}{*}{$\begin{array}{l}\text { Quality and quantity } \\
\text { of information transfer }\end{array}$} & \multirow{2}{*}{$\begin{array}{c}\text { 22q11.2DS } \\
(n=18) \\
\begin{array}{c}\text { Median } \\
I Q R \\
\text { range }\end{array}\end{array}$} & \multirow{2}{*}{$\begin{array}{c}\text { TD CA } \\
(n=18)\end{array}$} & \multirow{2}{*}{$\begin{array}{c}\text { TD RVAE } \\
(n=18) \\
\begin{array}{c}\text { Median } \\
I Q R \\
\text { range }\end{array}\end{array}$} & \multicolumn{3}{|c|}{$\begin{array}{l}\text { Pairwise comparison } \\
\text { 22q11.2DS-TD CA }\end{array}$} & \multicolumn{3}{|c|}{$\begin{array}{c}\text { Pairwise comparison } \\
\text { 22q11.2DS-TD RVAE }\end{array}$} \\
\hline & & & & $T$ & & $\begin{array}{l}\text { Effect size } r \\
95 \% \mathrm{CI}\end{array}$ & $T$ & $p$ & $\begin{array}{c}\text { Effect size } \\
r \\
95 \% \mathrm{CI}\end{array}$ \\
\hline $\begin{array}{l}\text { Perspective-taking (APT) } \\
\text { Information Transfer Score } \\
\text { (max.100) }\end{array}$ & $\begin{array}{c}80.00 \\
73.75-83.00 \\
59.00-89.00\end{array}$ & $\begin{array}{c}82.00 \\
79.50-87.25 \\
74.00-91.00\end{array}$ & $\begin{array}{c}78.00 \\
74.25-80.25 \\
63.00-86.00\end{array}$ & 128.50 & $.014 *$ & $\begin{array}{c}-.41 \\
{[-.65,-.09]}\end{array}$ & 34.50 & $.026^{*}$ & $\begin{array}{c}-.37 \\
{[-.62,-.05]}\end{array}$ \\
\hline Total number of utterances & $\begin{array}{c}25.50 \\
21.75-34.50 \\
19.00-47.00\end{array}$ & $\begin{array}{c}20.50 \\
17.00-25.75 \\
15.00-36.00\end{array}$ & $\begin{array}{c}19.00 \\
16.00-25.00 \\
12.00-35.00\end{array}$ & 26.50 & $.018^{*}$ & $\begin{array}{c}-.40 \\
{[-.64,-.08]}\end{array}$ & 29.00 & $.014 *$ & $\begin{array}{c}-.41 \\
{[-.65,-.09]}\end{array}$ \\
\hline MLU (words) & $\begin{array}{c}5.88 \\
5.65-6.48 \\
3.55-7.95\end{array}$ & $\begin{array}{c}7.60 \\
6.60-8.62 \\
6.45-9.08\end{array}$ & $\begin{array}{c}6.72 \\
6.40-7.41 \\
5.39-8.93\end{array}$ & 170.00 & $<.001 *$ & $\begin{array}{c}-.61 \\
{[-.78,-.35]}\end{array}$ & 156.00 & $.002 *$ & $\begin{array}{c}-.51 \\
{[-.72,-.22]}\end{array}$ \\
\hline ML5LU (words) & $\begin{array}{c}9.70 \\
8.75-10.45 \\
4.80-12.20\end{array}$ & $\begin{array}{c}11.80 \\
10.95-13.00 \\
8.80-16.80\end{array}$ & $\begin{array}{c}10.10 \\
9.20-12.00 \\
8.40-14.80\end{array}$ & 169.00 & $<.001 *$ & $\begin{array}{c}-.61 \\
{[-.78,-.35]}\end{array}$ & 110.00 & $.031 *$ & $\begin{array}{c}-.36 \\
{[-.62,-.08]}\end{array}$ \\
\hline $\begin{array}{l}\text { Role-taking (CRT) } \\
\text { Total score (max.16) }\end{array}$ & $\begin{array}{c}12.00 \\
9.50-13.25 \\
6.00-16.00\end{array}$ & $\begin{array}{c}13.00 \\
10.75-15.00 \\
6.00-16.00\end{array}$ & $\begin{array}{c}10.00 \\
8.75-13.25 \\
8.00-16.00\end{array}$ & 104.00 & . 189 & $n s$ & 78.00 & .742 & $n s$ \\
\hline
\end{tabular}

$\mathrm{TD}=$ typically developing; $\mathrm{CA}$ = chronological age; RVAE = Receptive Vocabulary Age Equivalent; $\mathrm{CI}=\mathrm{Confidence} \mathrm{Interval;} \mathrm{IQR} \mathrm{=} \mathrm{Interquartile} \mathrm{Range}$ * Significant difference when False Discovery Rate control (Benjamini \& Hochberg, 1995) applied for multiple testing $n s$ Non-significant difference when False Discovery Rate control applied, no effect sizes calculated. 
Table VI. Descriptive statistics of manner and relevance measures in Action Picture Test (APT) and Communicative Role-Taking (CRT) test across groups

\begin{tabular}{|c|c|c|c|c|c|c|c|c|c|}
\hline \multirow[b]{2}{*}{$\begin{array}{l}\text { Manner and relevance } \\
\text { of information transfer }\end{array}$} & \multirow{2}{*}{$\begin{array}{c}\text { 22q11.2DS } \\
(n=18) \\
\text { Median } \\
I Q R \\
\text { range }\end{array}$} & \multirow{2}{*}{$\begin{array}{c}\text { TD CA } \\
(n=18) \\
\begin{array}{c}\text { Median } \\
I Q R \\
\text { range }\end{array}\end{array}$} & \multirow{2}{*}{$\begin{array}{c}\text { TD RVAE } \\
(n=18) \\
\begin{array}{c}\text { Median } \\
I Q R \\
\text { range }\end{array}\end{array}$} & \multicolumn{3}{|c|}{$\begin{array}{l}\text { Pairwise comparison } \\
\text { 22q11.2DS-TD CA }\end{array}$} & \multicolumn{3}{|c|}{$\begin{array}{c}\text { Pairwise comparison } \\
\text { 22q11.2DS-TD RVAE }\end{array}$} \\
\hline & & & & $T$ & & $\begin{array}{c}\text { Effect size } r \\
95 \% \mathrm{CI}\end{array}$ & $T$ & $p$ & $\begin{array}{c}\text { Effect size } \\
r \\
95 \% \mathrm{CI}\end{array}$ \\
\hline \multicolumn{10}{|l|}{ Perspective-taking (APT) } \\
\hline Proportion T-units & $\begin{array}{c}.56 \\
.47-.65 \\
.33-.87\end{array}$ & $\begin{array}{c}.73 \\
.64-.81 \\
.49-.95\end{array}$ & $\begin{array}{c}.75 \\
.61-.87 \\
.40-.92\end{array}$ & 131.00 & $.010^{*}$ & $\begin{array}{c}-.43 \\
{[-.67,-.12]}\end{array}$ & 136.00 & $.005^{*}$ & $\begin{array}{c}-.47 \\
{[-.62,-.05]}\end{array}$ \\
\hline Proportion I-units & $\begin{array}{c}.04 \\
.00-.10 \\
.00-.23\end{array}$ & $\begin{array}{c}.00 \\
.00-.00 \\
.00-.13\end{array}$ & $\begin{array}{c}.00 \\
.00-.08 \\
.00-.31\end{array}$ & 6.00 & $.016^{*}$ & $\begin{array}{c}-.40 \\
{[-.64,-.08]}\end{array}$ & 21.00 & .508 & $\begin{array}{c}-.41 \\
{[-.65,-.09]}\end{array}$ \\
\hline \multicolumn{10}{|l|}{ Role-taking (CRT) } \\
\hline Proportion A-answers & $\begin{array}{c}.63 \\
.47-.75 \\
.13-1.00\end{array}$ & $\begin{array}{c}.75 \\
.59-.88 \\
.25-1.00\end{array}$ & $\begin{array}{c}.56 \\
.38-.78 \\
.13-1.00\end{array}$ & 106.00 & .155 & $n s$ & 55.00 & .495 & $n s$ \\
\hline $\begin{array}{l}\text { Proportion B1-answers } \\
\text { (vague word choice) }\end{array}$ & $\begin{array}{c}.13 \\
.00-.13 \\
.00-.38\end{array}$ & $\begin{array}{c}.13 \\
.00-.25 \\
.00-.38\end{array}$ & $\begin{array}{c}.13 \\
.00-.25 \\
.00-.50\end{array}$ & 64.00 & .812 & $n s$ & 61.50 & .070 & $n s$ \\
\hline $\begin{array}{l}\text { Proportion B2-answers } \\
\text { (wrong comm. function) }\end{array}$ & $\begin{array}{c}.13 \\
.00-.13 \\
.00-.25\end{array}$ & $\begin{array}{c}.00 \\
.00-.25 \\
.00-.13\end{array}$ & $\begin{array}{c}.13 \\
.00-.13 \\
.00-.25\end{array}$ & 0.00 & $.008 *$ & $\begin{array}{c}-.44 \\
{[-.67,-.13]}\end{array}$ & 45.00 & .593 & $n s$ \\
\hline $\begin{array}{l}\text { Proportion C-answers } \\
\text { (off-topic) }\end{array}$ & $\begin{array}{c}.19 \\
.09-.28 \\
.00-.50\end{array}$ & $\begin{array}{c}.13 \\
.00-.25 \\
.00-.38\end{array}$ & $\begin{array}{c}.13 \\
.00-.38 \\
.00-.38\end{array}$ & 7.00 & .119 & $n s$ & 51.50 & .624 & $n s$ \\
\hline
\end{tabular}

$\mathrm{TD}=$ typically developing; $\mathrm{CA}=$ chronological age $\mathrm{RVAE}=$ Receptive Vocabulary Age Equivalent $\mathrm{CI}=$ Confidence Interval; IQR = Interquartile Range; comm. = communicative *Significant difference when False Discovery Rate control (FDR, Benjamini \& Hochberg, 1995) applied for multiple testing, $n s$ Non-significant difference when FDR control applied, no effect sizes calculated. 
Table VII. Spearman correlations between Action Picture Test Information Score (APT ITS) and Communicative Role Taking (CRT) parameters and chronological age (CA), Receptive Vocabulary Age Equivalents (RVAE) and Expressive Language Screening Composite Score (ELSCS).

\begin{tabular}{|c|c|c|c|c|c|c|}
\hline & \multicolumn{3}{|c|}{$22 \mathrm{q} 11.2 \mathrm{DS}(n=27)$} & \multicolumn{3}{|c|}{ TD group $(n=36)$} \\
\hline & $\mathrm{CA}$ & RVAE & ELSCS & $\mathrm{CA}$ & RVAE & ELSCS \\
\hline APT ITS & $.53 *$ & $.67 * *$ & $.66^{* *}$ & $.78^{* *}$ & $.77 * *$ & $.48^{* *}$ \\
\hline I-units & $n s$ & $-.64 *$ & $-.42 *$ & $-.47 * *$ & $-.47 * *$ & $-.54 * *$ \\
\hline Illogical elaborations & $-.40 *$ & $-.44^{*}$ & $-.61 * *$ & $-.42 * *$ & $-.48 * *$ & $n s$ \\
\hline CRT total score & $.40^{*}$ & $.56 * *$ & $.62 * *$ & $.57 * *$ & $.53 * *$ & $n s$ \\
\hline CRT A answers & $.57 * *$ & $.72 * *$ & $.70^{* *}$ & $.62 * *$ & $.59 * *$ & ns \\
\hline CRT B2 answers & $n s$ & $n s$ & $-.40 *$ & $-.52 * *$ & $-.52 * *$ & $n s$ \\
\hline
\end{tabular}

$n s=$ Non-significant association

*Correlation is significant at .05 level (2-tailed).

**Correlation is significant at .01 level (2-tailed).

\section{FIGURES}

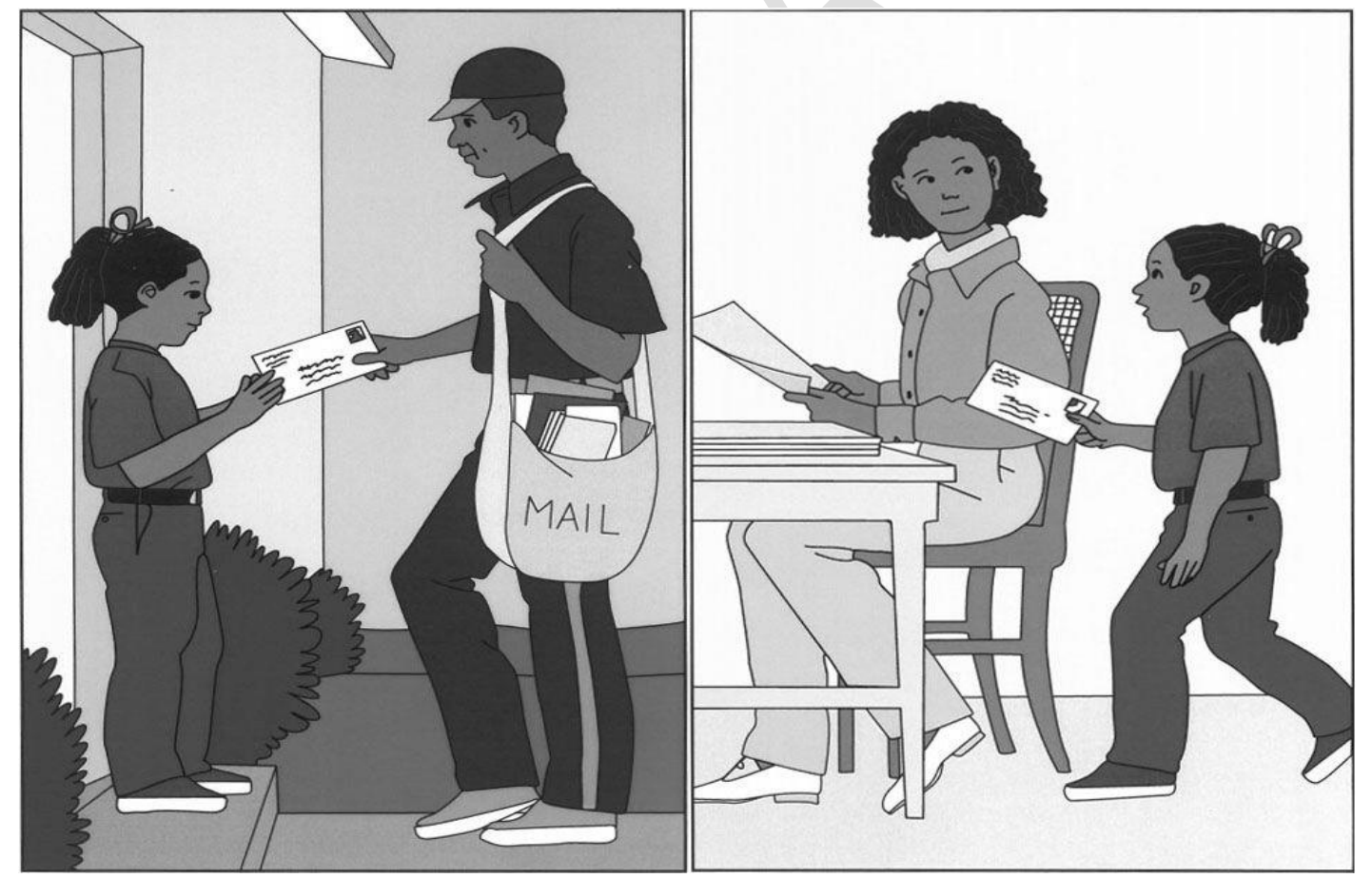

Figure 1. Example of Communicative Role-Taking item: a) "Look at what's happening here." b)

"Look at the girl: What is the girl telling her mother?". Diagnostic Evaluation of Language Variation (DELV NR, Seymour, Roeper, \& de Villiers, 2005). Copyright @ 2003 NCS Pearson, Inc. Reproduced with permission. All rights reserved. "Diagnostic Evaluation of Language Variation" is a trademark, in the US and/or other countries, of Pearson Education, Inc. or its affiliates. 


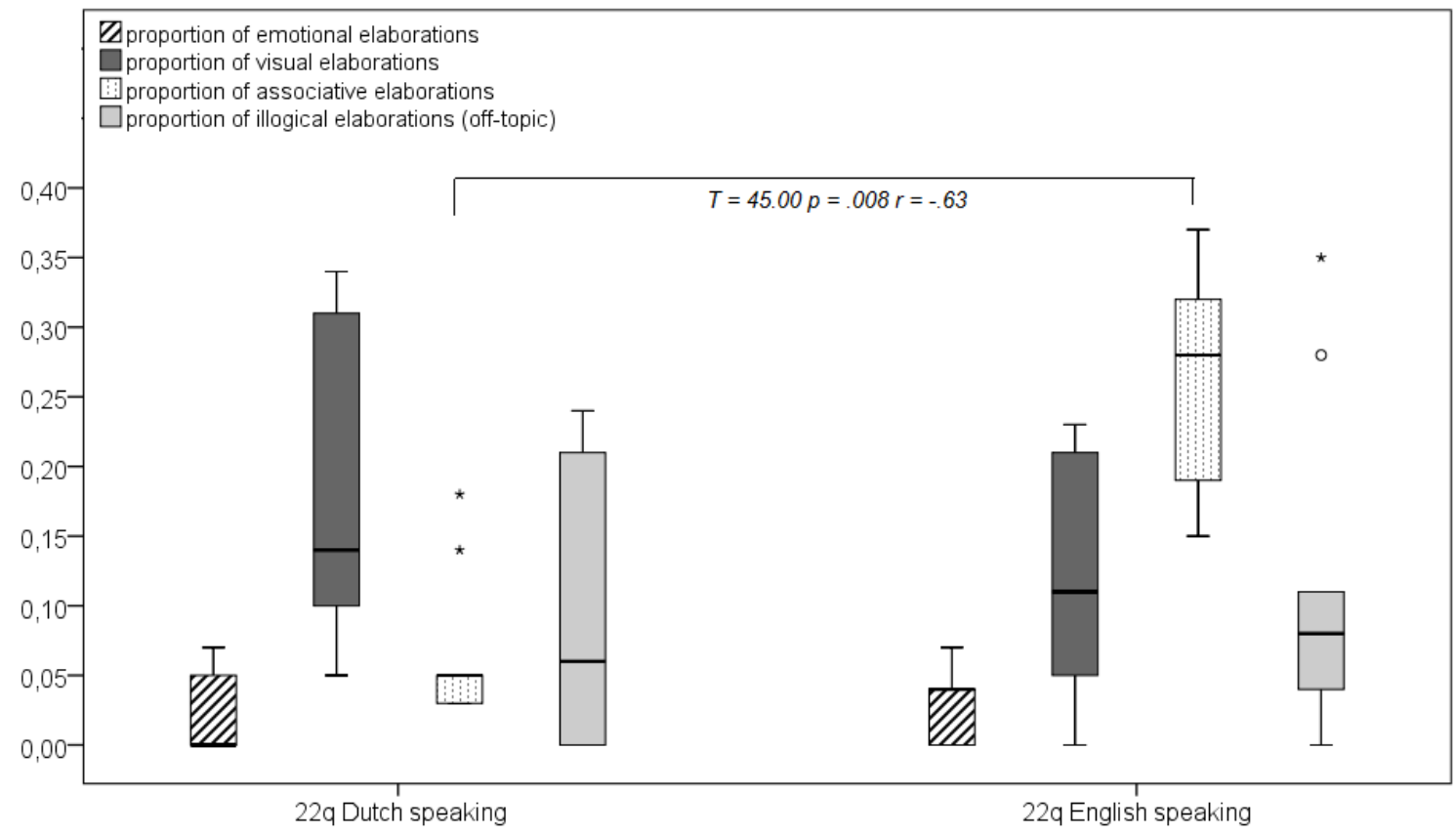

Figure 2. Boxplots representing proportions of types of elaborations in Action Picture Test (APT), a perspective-taking task, comparing Dutch-speaking children with 22q11.2DS $(n=9)$ to English-speaking children with 22q11.2DS $(n=9)$.

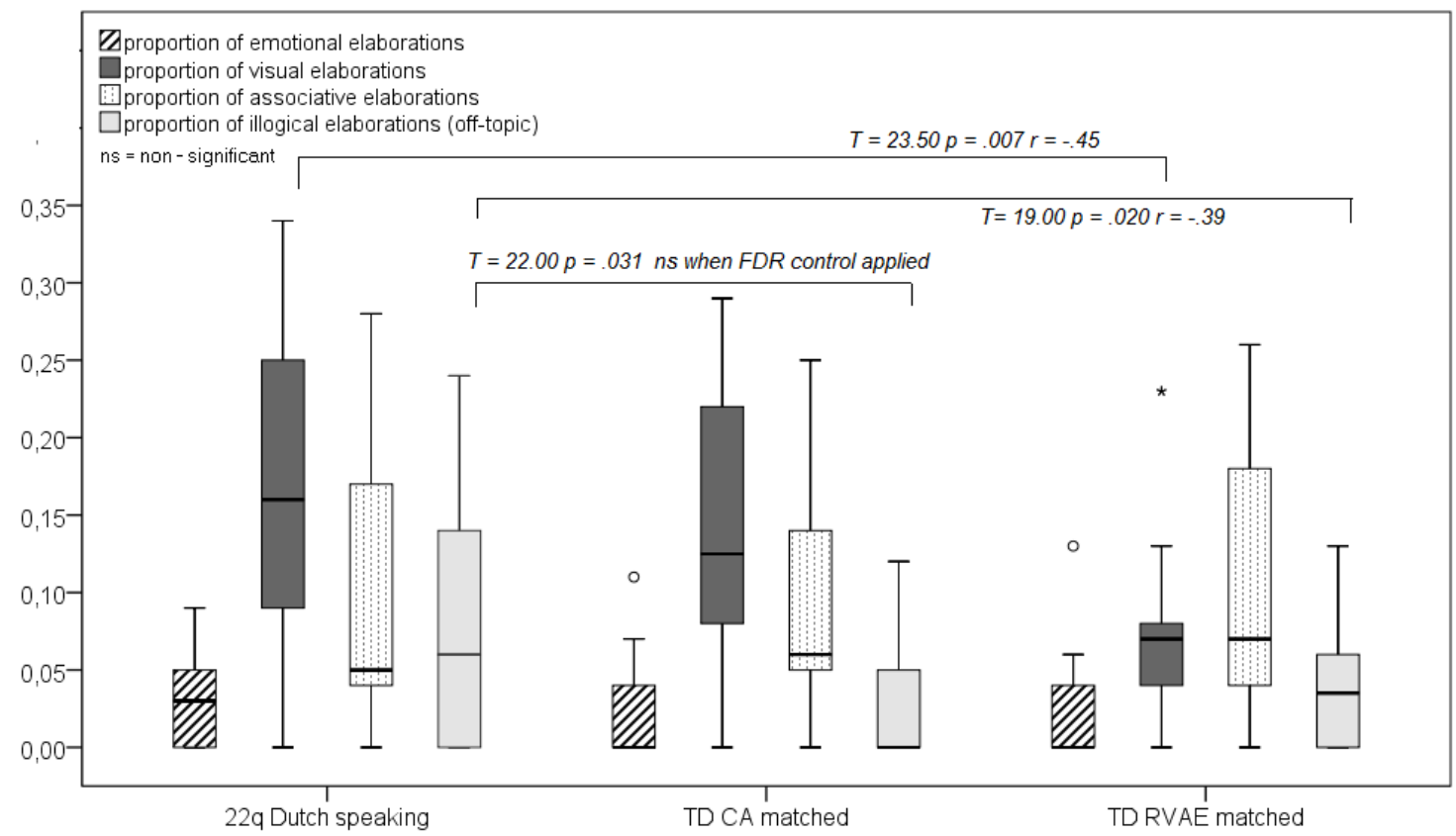

Figure 3. Boxplots representing proportions of types of elaborations in Action Picture Test (APT), a perspective-taking task, comparing Dutch-speaking children with 22q11.2DS ( $n=$ 18) to typically developing children pairwise matched for chronological age (TD CA, $n=18$ ), and to younger typically developing children pairwise matched for Receptive Vocabulary Age Equivalents (TD RVAE). 